The University of Maine

DigitalCommons@UMaine

Communication and Journalism Faculty

Scholarship

Communication and Journalism

2007

\title{
A Wavelength for Every Network: Synchronous Broadcasting and National Radio in the United States, 1926-1932
}

Michael J. Socolow

University of Maine, michael.socolow@maine.edu

Follow this and additional works at: https://digitalcommons.library.umaine.edu/cmj_facpub

Part of the Film and Media Studies Commons, History of Science, Technology, and Medicine Commons, Radio Commons, and the United States History Commons

\section{Repository Citation}

Socolow, Michael J., "A Wavelength for Every Network: Synchronous Broadcasting and National Radio in the United States, 1926-1932" (2007). Communication and Journalism Faculty Scholarship. 1.

https://digitalcommons.library.umaine.edu/cmj_facpub/1 


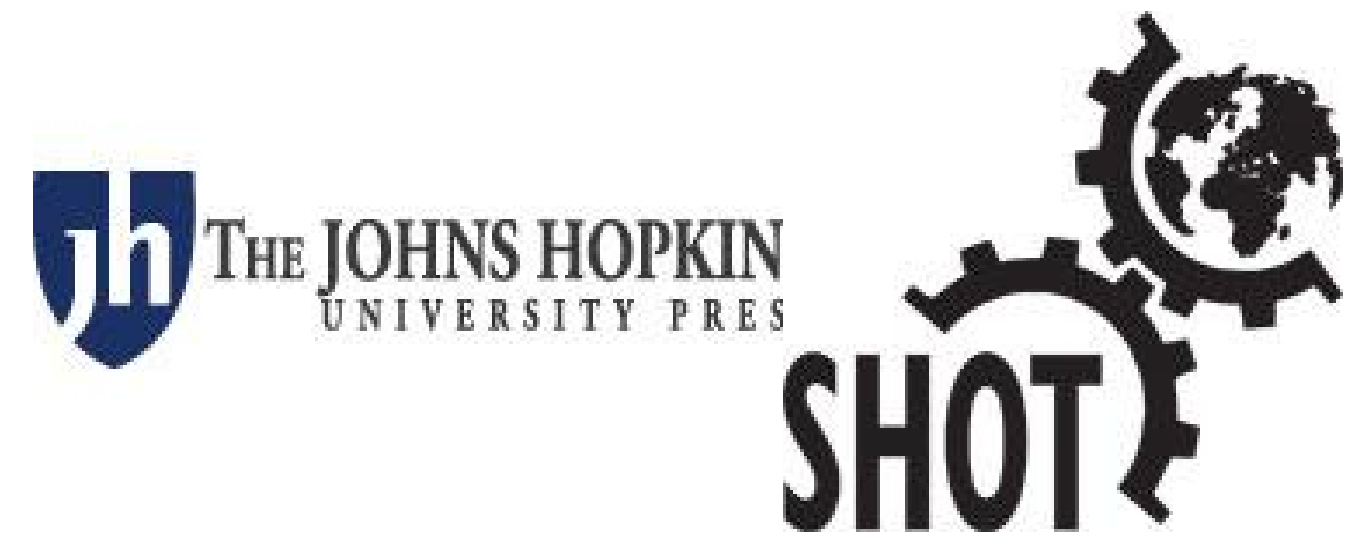

A Wavelength for Every Network: Synchronous Broadcasting and National Radio in the United States, 1926-1932 Author(s): Michael J. Socolow

Source: Technology and Culture, Vol. 49, No. 1 (Jan., 2008), pp. 89-113

Published by: The Johns Hopkins University Press and the Society for the History of Technology

Stable URL: http://www.jstor.org/stable/40061379

Accessed: 07-06-2016 21:28 UTC

Your use of the JSTOR archive indicates your acceptance of the Terms \& Conditions of Use, available at http://about.jstor.org/terms

JSTOR is a not-for-profit service that helps scholars, researchers, and students discover, use, and build upon a wide range of content in a trusted digital archive. We use information technology and tools to increase productivity and facilitate new forms of scholarship. For more information about JSTOR, please contact support@jstor.org.

The Johns Hopkins University Press, Society for the History of Technology are collaborating with JSTOR to digitize, preserve and extend access to Technology and Culture 


\title{
A Wavelength for Every Network
}

\author{
Synchronous Broadcasting and National Radio \\ in the United States, 1926-1932
}

\section{MICHAEL J. SOCOLOW}

Today he is remembered as the "father of Silicon Valley." ${ }^{1}$ But before he introduced David Packard to William Hewlett and before being named provost of Stanford University, Frederick Terman was a prodigy in the field of radio engineering. On 20 March 1929, the twenty-eight-year-old Stanford University engineering professor offered the San Francisco section of the Institute of Radio Engineers a revolutionary vision for American broadcasting. Terman explained how tests of a new system-called isochronous, or "synchronous," broadcasting-made feasible a network radio structure in which " 30 chains averaging 100 stations each might put 30 programs within reach of practically every listener in the country." The problem of regulating broadcast licenses would be significantly eased; in fact, Terman concluded that "the ultimate problem of broadcasting may be to find enough stations to fill up the chains." ${ }^{2}$

Simply stated, synchronous broadcasting is the process of precisely synchronizing the transmission of identical wavelengths by two or more broadcast transmitters. By 1929, the system had already been proven effective, as stations WBZ and WBZA in Massachusetts both broadcast at 990 kilocycles without significant interference problems. Terman and others envisioned a national system in which any prospective network could be assigned a wavelength, and with proper application of the synchronous tech-

Michael J. Socolow is an assistant professor in the Department of Communication and Journalism at the University of Maine. His scholarship focuses on issues of competition in the first two decades of national broadcasting.

(C)2008 by the Society for the History of Technology. All rights reserved. 0040-165X/08/4901-0005/89-113

1. Stuart W. Leslie and Robert H. Kargon, "Selling Silicon Valley: Frederick Terman's Model for Regional Advantage," Business History Review 70 (1996): 435-72.

2. Frederick Emmons Terman, "Some Possibilities of Intelligence Transmission When Using a Limited Band of Frequencies," Proceedings of the Institute of Radio Engineers 18 (January 1930): 167. 
JANUARY

2008

VOL. 49

nique, that network's signal would be transmitted by multiple outlets across the nation. Under such a system, radio listeners anywhere within the country might find one of the National Broadcasting Company's (NBC) two networks at 660 kilocycles, or the Columbia Broadcasting System's (CBS) network at $\mathbf{8 8 0}$ kilocycles. By freeing up the numerous wavelengths employed for network radio, significantly more broadcasters - at the local, regional, and national levels-could be accommodated.

Synchronous broadcasting was not simply a futuristic vision. By the end of 1930, NBC's general engineer acknowledged its technical feasibility. Elsewhere, the British Broadcasting Corporation (BBC) began experimental synchronization in 1926, and German and Swedish broadcasters started using the system in $1930 .{ }^{3}$ In the U.S. context, the synchronous system (also called "synchronization") promised to alleviate tensions caused by the rapid expansion of NBC and CBS during the late 1920s and early 1930s. One such issue, regularly brought to the attention of regulators and politicians by irate radio listeners, was "program duplication." As the networks expanded, national programming transmitted by multiple stations on several different wavelengths seemed to diminish the diversity of programming on U.S. airwaves. Program duplication joined other contentious debates emerging in broadcasting's earliest era, including discussions of advertising on the airwaves and the apparent favoritism toward commercial broadcasters shown by federal regulators.

These disputes testify to the vitality of early public debate over broadcasting's influence on American society. Radio's revolutionary characteristics-its creation of a new public sphere, a social arena both massively public and intimately personal—required novel policy considerations. Politicians, broadcasters, critics, regulators, and engineers all wrestled with broadcasting's role in the U.S. context. Issues such as the proper mode of regulation, applicable technical specifications, the acceptability of advertising, the boundaries of speech, and the optimal number of broadcasters were deeply intertwined; no single aspect of broadcasting could be addressed in isolation. Broadcasting, from its birth, stood athwart a nexus of technological, cultural, political, and social considerations. ${ }^{4}$

3. C. W. Horn, "The Importance of Phase Control in Synchronizing," Electronics, December 1930, 423; "NBC Admits Practicability of Synchronizing," Electronics, November 1930, 364; L. McC. Young, "Present Practice in the Synchronous Operation of Broadcast Stations as Exemplified by WBBM and KFAB," Proceedings of the Institute of Radio Engineers 21 (1936): 438-39.

4. Robert J. Brown, Manipulating the Ether: The Power of Broadcast Radio in Thirties America (Jefferson, N.C., 1998); Douglas B. Craig, Fireside Politics: Radio and Political Culture in the United States, 1920-1940 (Baltimore, 2000); Michele Hilmes, Radio Voices: American Broadcasting, 1922-1952 (Minneapolis, 1997); Bruce Lenthall, Radio's America: The Great Depression and the Rise of Modern Mass Culture (Chicago, 2007); Jason Loviglio, Radio's Intimate Public: Network Broadcasting and Mass-Mediated Democracy (Minneapolis, 2005); Edward D. Miller, Emergency Broadcasting and 1930s American Radio 
Synchronous broadcasting promised to reframe much of the debate. It addressed the issue of spectrum scarcity by offering the possibility of significantly more broadcast stations. By allowing more broadcasters on the air, synchronization would foster a more competitive broadcasting environment and provide the national audience an opportunity for more diverse programming. More effective exploitation of the broadcast spectrum had the potential to ease tensions surrounding federal regulation and licensing. While not completely solving the scarcity problem (for example, it would not allow an unlimited number of broadcasters), synchronous broadcasting provided a promising technical alternative to the status quo during the first two decades of U.S. broadcasting. Politicians, members of the Federal Radio Commission (FRC), and a sizable subset of the broadcasting community recognized its potential and enthusiastically embraced its democratic promise. In fact, the first regulation of network broadcasting in U.S. history was the commission's attempt, in 1929, to enforce synchronization. The industry press and the commercial networks-CBS and NBC-strongly opposed implementation of the system. By offering a more competitive marketplace in national broadcasting, synchronization threatened the commercial viability of the nascent network duopoly.

In a direct challenge to the deterministic and evolutionary narratives that have proliferated in the field, scholars of technology have increasingly emphasized failure at the center of historical inquiry. ${ }^{5}$ The failure to adopt synchronous broadcasting forces us to reconsider the scope of the earliest debates regarding American radio. Although the synchronization debate and the reform movement were catalyzed by similar anxieties, including fears about monopolization of the airwaves, homogenization and commercialization of culture, and corporations controlling speech on the public airwaves, the radio engineering community and the reformers failed to collaborate in promoting synchronous broadcasting. This article explores the reasons why synchronous broadcasting, despite its technical feasibility and social promise, never became a serious alternative to the status quo.

The public debate over synchronous broadcasting consisted of two related discussions. The first concerned the technical viability of the system; the second, which commenced shortly before viability was established, concerned economic and regulatory issues of implementation. Much of the first discussion can be reconstructed by referencing contemporaneous reports in the technical literature, but any scholar attempting to recount the second one faces archival obstacles. While the public record (including

(Philadelphia, 2003); Hugh Richard Slotten, Radio and Television Regulation (Baltimore, 2000), esp. 43-67.

5. Kenneth Lipartito, "Picturephone and the Information Age: The Social Meaning of Failure," Technology and Culture 44 (2003): 52-58; John M. Staudenmaier, S.J., "Rationality, Agency, Contingency: Recent Trends in the History of Technology," Reviews in American History 30 (2002): 168-81. 
JANUARY

2008

VOL. 49

press accounts, congressional testimony and debates, reports of the FRC, and other sources) is voluminous, there exist few archival sources related to synchronization. The NBC collections at both the Library of Congress and the Wisconsin Historical Society are not comprehensive and possess minimal engineering material from before 1935. Other evidence suggests that after synchronization's rejection as a national broadcasting system, NBC's engineers thought little of it. When NBC vice president and chief engineer O. B. Hanson recounted the history of NBC's engineering department before a Federal Communications Commission (FCC) hearing in November 1938, synchronization was barely mentioned. Hanson's testimony required almost ninety pages of text, of which synchronous broadcasting occupied less than one paragraph. ${ }^{6}$ The Radio Corporation of America (RCA) collection, housed in the Hagley Museum and Library, does not contain materials referencing synchronization during this period. ${ }^{7}$ Most of the material related to synchronization in the FRC collection at the National Archives is recapitulated in the commission's annual reports. While such archival obstacles have undoubtedly hindered historical examination of this subject, the contemporaneous technical sources, selected archival material, and records of public debate are clearly rich enough to reconstruct discussions of synchronization.

This article's recounting of the synchronization debate can be contextualized within the revisionist scholarship emphasizing conflict in the early negotiations over the social construction of U.S. broadcasting. Robert McChesney, Thomas Streeter, and others have chronicled the commercial broadcasting industry's efforts to obscure public dispute and propagate a narrative of ideological harmony in accounts of the evolution of the U.S. system of broadcasting. Similarly, Susan Smulyan has shown how debates concerning applicable technologies for national broadcasting were constricted by AT\&T and RCA. ${ }^{8}$ Synchronization was not the only alternative national broadcasting technology that the networks derailed by using their political, economic, and social leverage; the widespread use of electrical transcriptions and, after 1935, frequency modulation (FM) were also severely hampered by network efforts. ${ }^{9}$

6. Testimony of O. B. Hanson, Federal Communications Commission Docket No. 5060, 710-99.

7. Personal communication with Marjorie McNinch, Reference Archivist, Manuscripts and Archives Department, Hagley Museum and Library, Wilmington, Delaware, 19 June 2007.

8. Robert W. McChesney, Telecommunications, Mass Media, \& Democracy (New York, 1993); Thomas Streeter, Selling the Air: A Critique of the Policy of Commercial Broadcasting in the United States (Chicago, 1996); Craig; Kathy M. Newman, Radio Active: Advertising and Consumer Activism, 1935-1947 (Berkeley, Calif., 2004); Susan Smulyan, Selling Radio: The Commercialization of American Broadcasting, 1920-1934 (Washington, D.C., 1994), $11-64$.

9. On electrical transcriptions, see Alexander Todd Russo, "Defensive Transcriptions: 
The synchronization story also supports the scholarship of economists like Nobel laureate Ronald Coase, who question spectrum scarcity's validity as the basis for U.S. broadcast regulation. Spectrum scarcity was not simply an established, neutral, scientific fact: by providing the scientific rationale for discriminatory action, it privileged proponents of the regulatory system as it developed. ${ }^{10}$ The prime benefit of synchronization was its ability to create a far more effective exploitation of the broadcast spectrum. The failure of the FRC to implement a system addressing the major physical limitation on U.S. broadcasting attests to spectrum scarcity's political and economic value to the commercial broadcasting community.

Synchronization threatened chaos for the carefully rationalized U.S. broadcasting marketplace. As this article will show, synchronization was technically feasible though economically unpalatable for the networks and much of the commercial broadcasting community. Public criticism of CBS and NBC created the initial pressure to adopt the system. But when the listening audience's dissatisfaction with the radio chains lessened during the early 1930s, demands for the networks and the FRC to institute synchronization ceased. Fears of corporate monopolization of the airwaves dissipated as the U.S. audience grew fond of its national network programming. Discussions of synchronization would continue in the technical literature, but wider public discussion essentially vanished from the historical record.

\section{Synchronous Broadcasting's Technological Development}

The technical feasibility of synchronous broadcasting began with the development of the piezo-electric crystal oscillator, an important though too-often-overlooked moment in the early history of broadcasting. ${ }^{11}$ The

Radio Networks, Sound-on-Disc Recording, and the Meaning of Live Broadcasting," The Velvet Light Trap 54 (2004): 4-17, and "Roots of Radio's Rebirth: Audiences, Aesthetics, Economics, and Technologies of American Broadcasting, 1926-1951" (Ph.D. diss., Brown University, 2004). On FM, see Don V. Erickson, Armstrong's Fight for FM Broadcasting: One Man vs. Big Business and Bureaucracy (Montgomery, Ala., 1973); Lawrence Lessing, Man of High Fidelity (Philadelphia, 1956); and Tom Lewis, Empire of the Air: The Men Who Made Radio (New York, 1991).

10. Ronald H. Coase, "The Federal Communications Commission," Journal of Law \& Economics 2 (1959): 1-40; Ronald H. Coase and Nicholas Johnson, "Should the FCC Be Abolished?" in Regulation, Economics, and the Law, ed. Bernard H. Siegan (Lexington, Mass., 1979), 47-53; Thomas W. Hazlett, "Liberalizing U.S. Spectrum Allocation," Telecommunications Policy 27 (2003): 485-99; David Moss and Michael R. Fein, "Radio Regulation Revisited: Coase, the FCC, and the Public Interest," Journal of Policy History 15 (2003): 389-416; Louise Benjamin, Freedom of the Air and the Public Interest: First Amendment Rights in Broadcasting to 1935 (Carbondale, Ill., 2001), 203-25; McChesney, 239-51.

11. Young (n. 3 above), 433; S. R. Winters and Geo. S. Turner, "When the Magic Crys- 
JANUARY

2008

VOL. 49

crystal's ability to offer far greater stability in the operating frequencies of radio transmitters significantly reduced heterodyne interference (static) and dramatically improved radio's tonal fidelity. Discussing the reduction of heterodyne interference in the mid-1920s, a key AT\&T engineer noted that there existed "no single contribution to this important problem so effective as the development of the piezo-electric crystal for use at radio frequencies." 12

The remarkable stability of the piezo crystal oscillator inspired engineers to explore the possibility of precisely synching multiple transmitters. Regular chain, or network, broadcasting had only recently commenced, and testing effective methods of national coverage inspired the first synchronous experiments. Between 1923 and 1926, Frank Conrad, Frank Falknor, Walter Evans, and other Westinghouse engineers sought to create just such a system. ${ }^{13}$ The WJZ radio chain, formed by Westinghouse, RCA, and General Electric (GE) (known collectively as the Radio Group), had been denied access to AT\&T telephone lines for the interconnection of broadcast stations. Embroiled in a contentious patent dispute, executives of both the Radio Group and the telephone company realized that the future of nation-al broadcasting hinged upon the ruling of an independent arbitrator en-gaged to settle the myriad issues involved. While awaiting the arbitrator's decision, the Westinghouse team began exploring technological alternatives to using dedicated AT\&T lines. They experimented with shortwave relay by transmitting programs from Pittsburgh to Chicago, where the signal was then converted to a standard broadcast frequency for re-broadcasting. This shortwave relay system was prone to selective fading and distortion, however, and this prompted a search for an alternative relay system. ${ }^{14}$ Conrad theorized that isochronous broadcasting could resolve several of the problems inherent in shortwave signal conversion. "The stations would operate simultaneously carrying identical programs, tied together by ... radio link," Evans later remembered.

Conrad's approach to synchronizing the waves was relatively simple: he would transmit a low-frequency tone generated by a tuning fork at one station, and at each of the synchronizing stations the audio tone from the tuning fork would be "multiplied up by means of suitable multi-vibrator cir-

tal Becomes the Magic Carpet," Radio Age, July 1926, 17; Paul Shubert, The Electric Word (New York, 1928), 290.

12. Laurens E. Whittemore, "The Development of Radio," Annals of the American Academy of Political and Social Science 142 (1929): 4.

13. A history of synchronization published in 1935 stated that Conrad first suggested the idea in 1924, while Falknor began the installation of the first system in January 1926; see Young, 433. See also Ann Graban Crawford, “A Universal Speaking Service: The Role of Westinghouse Electric and Manufacturing Company in the Development of National Network Broadcasting, 1922-1926," Journal of Broadcasting \& Electronic Media 51 (2007): 516-29.

14. "The Reminiscences of Donald G. Little," Radio Pioneers Project, Oral History Research Office, Columbia University, New York (hereafter RPP), 35-36; Smulyan (n. 8 above), 48-52. 
cuits to the assigned frequency of the station so that the carrier waves of both stations were held in complete synchronism." 15 The initial experiments were promising, but testing had barely begun when the motivating force behind Westinghouse's relay work vanished. The arbiter's ruling resulted in the creation of the National Broadcasting Company in 1926; this, the nation's sole network, would be owned by the Radio Group but would use only leased AT\&T lines for station interconnection. ${ }^{16}$

The development of NBC did not, however, stop technical experimentation in synchronous broadcasting. Just a few months before NBC's debut, two Westinghouse stations in Massachusetts started to synchronize their signals: WBZ in Boston and WBZA in Springfield began experimentally transmitting with the same frequency-900 kilocycles. ${ }^{17}$ The early tests proved remarkably successful; within weeks, the two stations established a permanent isochronous link that could have served as a national model. Radio Broadcast applauded the result, noting that "the release of many wavelengths" would occur if such synchronization was applied to network broadcasting. Throughout the synchronization debates, the successful WBZ-WBZA example highlighted the weakness of the argument for rejection on technical grounds. ${ }^{18}$ The stations, which were almost exactly 100 miles apart, were connected by a dedicated, modified telephone circuit, and transmissions were monitored closely for heterodyne problems. The stations did not interfere with each other-not even in their overlapping bordering zones-and the synchronized signal greatly increased the reception area of both without an increase in power.

Westinghouse's synchronization was known as a "wire control" system. By mid-1927, alternative isochronous control systems would be proposed and tested. A variation of shortwave re-broadcasting, called "shortwave control," consisted of multiple transmitters with identical crystals converting and synchronizing an incoming shortwave signal. This method had yet to be tried and appeared quite difficult, ${ }^{19}$ requiring perfectly matched crystals maintained at identical temperatures. While many broadcast engineers were skeptical, manufacturers of crystal control apparatus assured them that they

15. "The Reminiscences of Walter C. Evans," RPP, 41.

16. Erik Barnouw, A History of Broadcasting in the United States, vol. 1: A Tower in Babel (New York, 1966), 151-53.

17. The 11 November 1928 spectrum reallocation required $\mathrm{WBZ}$ and WBZA to change their frequency to 990 kilocycles; Young (n. 3 above), 434.

18. "Operating Two Stations on One Wavelength," Radio Broadcast, September 1926, 374; Westinghouse Electric \& Manufacturing Company, Facts about Westinghouse Radio Stations WBZ-WBZA in New England, pamphlet 2648 (Pittsburgh, 1931), 6, and "Broadcast Advertising in New England and New York: The WBZ-WBZA Market," in Questions and Answers: Broadcast Advertising, pamphlet 2704 (Westinghouse Radio Stations, Inc., 1929), both pamphlets in the Library of American Broadcasting, University of Maryland, College Park.

19. "Test Short Waves to Attune Stations," New York Times, 29 November 1927, 32. 
JANUARY

2008

VOL. 49

could produce "crystals so accurately matched that no audible heterodyne interference will result between two stations so controlled." An additional alternative was "carrier-wave" synchronization. This system required the synchronizing station to set up a receiving set several miles from its transmitter, in a location conducive to capturing the carrier wave of the signal to be synchronized. The originating signal would then be transmitted by telephone line to the synchronizing station's control room, where it would be amplified and its frequency precisely synchronized before being transmitted. Because of the vagaries of reception, this method required an engineer to monitor and equalize the signal during the synchronization. Interestingly, carrier-wave synchronization did not require identical programming; if the synchronization was precise enough, two stations could carry two different programs on the same wavelength, and there would be only minimal crosstalk and signal interference in the bordering reception areas. ${ }^{20}$

Successful examples of synchronous broadcasting are remarkable in light of the chaos that ensued in U.S. broadcasting from the fall of 1926 until the completion of the reallocation of the spectrum in November 1928. "The year 1926 is still remembered as marking the low point of quality in radio reception," noted radio critic Dane Yorke in a 1931 American Mercury article. ${ }^{21}$ The decision in United States v. Zenith Radio Corporation et al. (1926) resulted in hundreds of new stations jamming the airwaves during the fall of 1926. These new broadcasters jumped into the ether, happily squatting on long-held wavelengths and causing bedlam-not to mention an enormous increase in heterodyne interference and cross-talk-across the spectrum. To arrest the situation, Congress passed the Federal Radio Act and empowered the Federal Radio Commission to begin regulation of the airwaves "in the public interest, convenience, and necessity."

\section{The Federal Radio Commission, Congress, and Synchronous Broadcasting}

The unregulated ether provided the immediate stimulus for the creation of the Federal Radio Commission. But a secondary motivation, one cited by several skeptical legislators who voted for the Radio Act against their political inclinations, was that the FRC could provide an effective bulwark against monopolization of U.S. broadcasting. As Representative Ewin Davis (a Democrat from Tennessee) explained, the commissioners were appointed to look "after the radio situation in the interest of all the people and of all the users of radio and all those who are interested in it and the various sections of the country." Davis condemned the commission's

20. "Five Methods for Operating Radio Chains on One Wave," New York Times, 4 December 1927, 14.

21. Dane Yorke, “The Radio Octopus,” American Mercury, August 1931, 392. 
initial actions, complaining that commissioners "regarded it to be their duty solely ... to see how much of the air they could put in the control of the great radio corporations of the country." 22

Shortly after the passage of the act, Davis added an amendment requiring the equitable distribution of spectrum assignments according to geographic zones. The rapid expansion of the radio chains, which were based in New York City, created the necessity for the amendment. "We want broadcast licenses fairly distributed in such a manner that those who desire to do so may listen to New York and chain stations when they want to, but may, when they so desire, listen to programs broadcast by stations elsewhere throughout the country, including their own zones, states, and cities," Davis explained. ${ }^{23}$

The Davis Amendment (passed by both houses and signed into law) provided the strongest political defense of localism in broadcast history. Animated by a fear of cultural intrusion, the law addressed the issue of network expansion. For many radio listeners, the expansion of NBC, and, after 1927, CBS foretold "the death of long-distance listening." ${ }^{24}$ The standardized programming transmitted by affiliates of the chains angered those who enjoyed the possibility of tuning in different broadcasts from Denver or Detroit or Boston on any given evening. The problem went by several names, but was commonly referred to as "program duplication." Listeners irritated by program duplication wrote to stations, networks, the nascent FRC, and, perhaps most importantly, their congressional representatives. Senator Alben Barkley (a Democrat from Kentucky) complained of the "lack of activities of the Radio Commission with respect to chain broadcasting stations [despite the] many protests from people in our states." Barkley was seconded by Senator Sam Bratton (a Democrat from New Mexico), who informed his colleagues that "the complaint [in New Mexico] is against chain broadcasting, emanating principally from New York. The people there do not want that broadcasting. They prefer the independent stations." Senator William Harris (a Democrat from Georgia) joined the chorus when he entered a letter from a constituent embittered by program duplication into the Congressional Record. Col. W. E. Simmons, an avid radio listener, called on Harris to abolish NBC in the forthcoming legislative debates over radio. ${ }^{25}$

22. Congressional Record, 70th Cong., 1st sess., 1928, 69:4243; see also Jennifer M. Proffitt and Michael Brown, "Regulating the Radio Monopoly: Ewin Davis and His Legislative Debates, 1923-1928," Journal of Radio Studies 11 (2004): 100-115.

23. Congressional Record, 70th Cong., 1st sess., 1928, 3985.

24. Barnouw (n. 16 above), 207; Clifford Doerksen, American Babel: Rogue Radio Broadcasters of the Jazz Age (Philadelphia, 2005), 92-104; and Derek Vaillant, "BareKnuckled Broadcasting: Enlisting Manly Respectability and Racial Paternalism in the Battle against Chain Stores, Chain Stations, and the Federal Radio Commission on Louisiana's KWKH, 1924-33," The Radio Journal: International Studies in Broadcast and Audio Media 1 (2004): 193-211.

25. Congressional Record, 70th Cong., 1st sess., 1928, 5157, 5163-64. 
Members of the larger broadcasting community were well aware of this sentiment. In a letter to the FRC, the general manager of Chicago station WBBM proposed one version of synchronization as the solution to program duplication:

Give to each chain now in existence or which may be organized,

JANUARY

2008

VOL. 49 a certain air channel. When a broadcast is given by the chain over several stations, each station should be compelled to change its wavelength to the wavelength of the chain's key station.... This would in no way interfere with the chain broadcasts, but it would permit more programs. It would in fact simplify matters for the listeners. For instance, if the channel of the XYZ chain was 430 meters, the listeners would always know just where to pick up the programs from that chain. ${ }^{26}$

This impractical proposal-forcing stations to regularly change frequencies-would have created havoc for listener and broadcaster alike, but nevertheless provides evidence that factions within the commercial broadcasting community sought to restrict the number of wavelengths made available for chain programming.

Representative Davis proved the most consistently enthusiastic promoter of synchronization throughout 1927-28. In a January 1928 hearing, Davis pointedly asked the chairman of the FRC, Eugene Sykes, why, if synchronization worked for WBZ and WBZA, it would not work for the entire network system. The chairman replied that because the system required a plethora of "experienced engineers and highly qualified technicians ... the high cost makes the method prohibitive." The success of WBZ-WBZA resulted from Westinghouse's generous commitment of resources, something that Sykes explained would not be possible to require of all chain stations. Testifying in the same hearings, Commissioner Orestes Caldwell proved much more sympathetic to Davis's argument; unlike Sykes, he admitted that "the present chain arrangement was unsatisfactory" and synchronous broadcasting offered a promising solution. ${ }^{27}$

When the Davis Amendment appeared before the Senate in the spring of 1928, several senators questioned Senator Clarence Dill (a Democrat from Washington), the chief author of the Radio Act, about the possibility of synchronization. "Will placing these chain stations on one wave length obviate the trouble we have in the south?" asked Senator Earle Mayfield (a Democrat from Texas). Dill offered a confused reply. While acknowledging the success of WBZ and WBZA in synchronization, he deferred to the

26. C. B. Smith to the Federal Radio Commission, reprinted in Radio Broadcast, July 1927, 162. See also “One Wave for the Chain," Radio Digest, 1 April 1927, 8.

27. "Says Radio Chains Got 21 of 25 Lanes," New York Times, 28 January 1928, 13; "Proposes to Limit Radio Chain System," New York Times, 1 February 1928, 20. 
"engineers who have been before the committee," stating that "it has not yet proved practicable and feasible to broadcast chain programs on one wavelength." The synchronization in Massachusetts, Dill explained, was costly to maintain. "Those stations are connected by wires that keep them on the same frequency, and it would cost literally millions and millions of dollars to connect all of the chain stations of the country in such a way as to be able to do that," he concluded. ${ }^{28}$ Senator Dill undoubtedly understood (because he mentioned it later in the same debate) that all chain broadcasting in 1928 was accomplished by wire connection. Thus his answer appears disingenuous at best.

The commission reacted to this pressure. In one of its first acts, it asked an employee of the Department of Commerce to review the over 3,000 letters received on the subject of chain broadcasting during 1926-27. "Chain broadcasting is either the greatest blessing or curse of broadcasting," the resulting report noted, stating that "the conclusion is dependent entirely upon either the location of the listener or his taste." ${ }^{29}$ Rural listeners in particular complained about program duplication. In response to congressional pressure and listener complaints, Commissioner Caldwell publicly called for synchronization. In a speech detailing the commission's stance, he discussed the problems identified by engineers in the earliest testing. The central issue concerned the precision of the synchronized tuning apparatuses: the slightest deviations caused different types of carrier-wave interaction and thus resulted in heterodynes sounding like whistles over huge reception areas. Yet perfect synchronization had been achieved, and further experimentation would undoubtedly assist in developing a method to more easily and cost-effectively stabilize the synchronized signals. This method must be discovered, Caldwell concluded, because "if stations on the same frequency can be accurately synchronized, it will be possible to utilize our present channels manifold [sic] more effectively." Caldwell directly connected the success of the WBZ-WBZA link to the future of chain broadcasting: "This plan offers an economic solution of the serious problem of chain-program operation, where 20 to 40 channels are now sometimes tied up with an identical program. If such chain programs could be limited to one or two channels, obviously many channels now tied up would be freed for other services." 30

The majority of the commission agreed with Caldwell and attempted to enforce synchronization. Federal Radio Commission General Order No. 43, promulgated on 8 September 1928, was the first network-broadcasting reg-

28. Congressional Record, 70th Cong., 1st sess., 1928, 5158, 5170-71.

29. Federal Radio Commission, Annual Report of the Federal Radio Commission (Washington, D.C., 1927), 8.

30. "Address by Commissioner Caldwell on Synchronization, October 14, 1927," in Second Annual Report of the Federal Radio Commission, app. H (Washington, D.C., 1928), 221. 
JANUARY

2008

VOL. 49

ulation of any kind in U.S. history. This order prohibited "two or more stations [from] broadcasting the same program for more than one hour unless the transmitters are more than three hundred miles apart, or the stations are operating on the same frequency, or [unless] special permission" was granted by the commission. ${ }^{31}$ The 300 -mile radius prohibited stations in Washington, D.C., Boston, and Philadelphia, for example, from carrying more than one hour of network programs originating in New York unless the multiple transmitters were "operating on the same frequency" or the broadcasters received special permission from the commission. General Order No. 43 had been originally proposed to take effect in March 1929, but the commission announced a delay in order to poll listeners across the country "to determine the public's attitude towards the proposed restriction" before making the rule effective. ${ }^{32}$

The implementation of the order proved problematic, showing the commission to be unrealistic in its demands. The Radio Act did not clearly endow the commission with the power to enforce such a rule. The order's broad mandate left unclear which station retained the right to the original broadcast, and which station(s) acted illegally in a non-synchronized system. These problems led to a series of postponements of the rule; ultimately, General Order No. 43 would be rescinded in December 1929. In rescinding the order, the commission claimed it needed adequate time "to investigate and determine whether chain programs are being unnecessarily duplicated, and to enable the commission to determine what progress has been made toward the successful operation of two or more stations on the same frequency in synchronism, either by wire connection or otherwise." ${ }^{33}$

The commission's failure to enforce its chain-broadcasting order frustrated its defenders in Congress, in particular angering Senator Dill. The recently completed reorganization of the radio spectrum resulted in thirtyeight of the nation's forty clear channels being assigned to chain-affiliated stations. According to Dill, this defeated the purpose of clear-channel broadcasting: it led to the consolidation, rather than the diversification, of programming on the U.S. airwaves. The commission's inaction, Dill posited, was the result of having too much work and too few people. ${ }^{34}$ Senator Robert La Follette, a Wisconsin Republican, suspected that something else held up enforcement. "Is there some influence preventing the commission from permitting that order to go into effect?" he asked Dill. "I am unable to

31. Laurence F. Schmeckebier, The Federal Radio Commission: Its History, Activities, and Organization (Washington, D.C., 1932), 52.

32. "Chain Broadcasting May Be Restricted," Broadcast Advertising, May 1929, 10.

33. "Radio Chain Order Waits," New York Times, 8 October 1928, 29; "Rescinds Old Order on Radio Chains," New York Times, 21 December 1929, 24. See also James C. Foust, Big Voices of the Air: The Battle over Clear Channel Radio (Ames, Iowa, 2000), 34.

34. Congressional Record, 70th Cong., 2d sess., 1929, 70:3749, 3752. 
answer the Senator's question as to why they continually postpone it," Dill responded, "but the fact is that they do, and that is the matter to which I am objecting." ${ }^{35}$ Responding to this pressure, Chairman Sykes announced his intention to put forth a new rule limiting the broadcast of chain programs to only one 5,000-watt (maximum) transmitter in any single state. "Why does the commission continuously find fault with us and our service," asked the exasperated NBC president, Merlin Aylesworth, "when there are 400 small stations throughout the country that go unmolested?" 36

The commission premised the rescission of General Order No. 43 upon additional experiments to determine the technical feasibility of synchronous broadcasting. For these experiments, which were conducted between 1929 and 1931, the commission required the cooperation of engineers from $\mathrm{NBC}, \mathrm{RCA}$, and a few powerful, commercially successful affiliates. While they did cooperate, ultimately the networks would successfully defend their established oligopoly in chain broadcasting by dismissing the promising results of these experiments.

\section{Synchronization and the Networks}

Program duplication resulted from an unsettled situation in U.S. broadcasting between the years 1926 and 1929. The reorganization of the radio spectrum under General Order No. 40 was not completed until November 1928. Before this reorganization, chains required multiple, often overlapping affiliation contracts with stations around the country in order to ensure adequate coverage for sponsors. In 1928, CBS signed affiliation agreements with three separate Chicago broadcasters, and NBC required five Chicago stations for its two networks. ${ }^{37}$ This inefficient system, which required the chains to occupy far more wavelengths than necessary, first became noticeable among most American listeners in 1927 and provoked the popular outcry against "monopolization of the air."

The networks were well aware of synchronized broadcasting. WBZ and WBZA were NBC affiliates, and Westinghouse's engineers worked closely with NBC's engineers (Westinghouse owned a minority stake in NBC at the time). Yet from its inception, the networks vigorously fought the idea of national synchronization. Publicly, they argued that the system was simply not technically reliable enough to ensure its successful implementation. They also undoubtedly harbored fears about the initial investment required for synchronization. During the initial debates over the system, NBC was

35. Congressional Record, 71st Cong., 1st sess., 1929, 71:3836.

36. "Protest Chain Order Proposed for Radio," New York Times, 2 November 1929, 19.

37. John W. Spalding, "1928: Radio Becomes a Mass Medium," Journal of Broadcasting 8 (1963-64): 33-34. 
JANUARY

2008

VOL. 49

still not a profitable company, and CBS would not realize its first profit until 1929.38 The profitability of national broadcasting was not yet a given before 1930, and with the advent of the Great Depression, the future of radio advertising was far from assured. Those calling for synchronization praised the enhanced competitive environment it would create; unsurprisingly, NBC and CBS were not interested in assisting the development of competition.

The networks were not alone in their opposition to implementation of a synchronous system. Their most important affiliates joined them in resisting this putative reorganization of the spectrum. Network affiliation offered an important brand identity for stations in a competitive market, and the most successful commercial stations relied upon both network compensation and local advertising revenue. Synchronization would have forced many affiliates to choose between remittance from the national networks or local advertising dollars. Because the established affiliation system was so technically inefficient in the redundancies it produced on the radio spectrum, far more stations profited than would be the case were the networks to cover the nation with a series of high-powered, synchronized transmitters. The networks preferred this technically inefficient yet soonto-be very profitable affiliation system. Both NBC and CBS owned several key local stations, which earned both national and local revenue in such important markets as Chicago, New York, Philadelphia, and Washington, D.C. If confined to a single national wavelength, the profits of these stations would have been seriously reduced.

The networks publicly defended the system's inefficiencies by attacking the economic and technical viability of synchronous broadcasting. In February 1928, Senator Dill called NBC president Merlin Aylesworth to testify before the Senate Interstate Commerce Committee. Aylesworth had opposed synchronization from NBC's inception; at a meeting of NBC's Board of Consulting Engineers in early 1927, Aylesworth suggested that Westinghouse end the synchronous operation of WBZ-WBZA. Frank Conrad "strongly objected" and Aylesworth withdrew the proposal. ${ }^{39}$ At the Senate's hearings a year later, Dill asked Aylesworth why NBC, and its parent company RCA, did not pursue synchronous broadcasting more vigorously. Dill specifically questioned whether synchronous broadcasting was "technically possible" as of that moment. "It is technically possible," Aylesworth replied, "but not technically practicable to do it." The problem, Aylesworth stated, was that NBC's imposition of the system on its affiliates would create serious problems for the chain, its partners, and advertisers

38. Federal Communications Commission, Report on Chain Broadcasting (Washington, D.C., 1941), 17, 24.

39. "Minutes of the Third Meeting of the Board of Consulting Engineers, March 15, 1927," National Broadcasting Company History Files, folder 780, Library of Congress, Washington, D.C. 
wishing to use both national and local radio facilities. The system would turn the chains and their affiliates into adversaries, forcing them to compete for the same national advertising accounts and damaging the economic structure of the industry in its infancy. "A great number of independent stations," testified Aylesworth, "have very definitely expressed themselves on the point that when and if the network is put on a single wavelength ... they will immediately drop the chain." Affiliated stations not owned by NBC such as WMAQ in Chicago would be immediately harmed by losing their most popular national programming, while NBC would be harmed by losing the prestige garnered by affiliation with Chicago's most important station.

The relationship between stations and chains was symbiotic, Aylesworth argued. They provided each other with economic and public-relations benefits. "To restrict any network, whether it be the National Broadcasting Company, or the Columbia chain, or any other, is to wreck the only medium of mass distribution of programs," Aylesworth concluded. Addressing the technical specifics of synchronization, Aylesworth reiterated the earlier testimony of NBC's engineers. The WBZ-WBZA wire-connected system would simply be too costly to implement, he argued. Dill then pressed him on the question of relay-based synchronization. $\mathrm{He}$ wanted to know specifically whether the issues being discussed were truly technical-or economic. "If it does develop to where they can keep the stations accurately enough on their frequency without this connecting wire, then your objection comes primarily from a business standpoint?" Dill asked. Aylesworth candidly replied, "Yes, sir." 40

Earlier in the hearing, Aylesworth suggested a conspiracy was afoot. He accused "some of the smaller broadcasters [of staying] on the air for four or five hours a night asking people to write in to the Senate and to the Commission and request that all chain broadcasting be put on one wave length." "It is quite natural that the average honest fellow who knows nothing about the technical or practical side should write," he said, arguing implicitly that the assembled legislators should ignore their constituent correspondence in favor of his testimony. ${ }^{41}$ Instead of ignoring his constituents, Representative Davis ignored him; shortly after Aylesworth testified, Davis pressured Chairman Sykes to force the chains into synchronization. "In spite of the statements of interested engineers to the contrary," he explained, "chain programs can be successfully broadcast on the same wavelength. It is certainly practical and feasible for the chain programs to be broadcast upon a very few wavelengths." Davis feared the commission would allow a disproportionate number of chain affiliates to broadcast over cleared channels. To

40. Senate Committee on Interstate Commerce, Federal Radio Commissioners: Hearing [s] before the Committee on Interstate Commerce, United States Senate, 70th Cong., 1st Sess., 1928, 224 and 289.

41. Ibid., 285. 
JANUARY

2008

VOL. 49

remedy this, he asked the commission to impose a general "limitation on power to be used by chain stations," but failing that, a limitation should go into effect "at least when they are broadcasting chain programs." 42

Throughout the debates over synchronized broadcasting, the networks were strongly supported by much of the industry press. Radio Broadcast rejected Commissioner Caldwell's initial call for synchronization, arguing that it was unrealistic. Even the most promising system required human intervention, and "if the whole broadcasting structure depended for frequency stability upon manual control, it would become a sorry mess." ${ }^{43}$ A year later, the editors of Radio Broadcast warned that those promoting synchronization were feeding a false hope. Dismissing the promising results of a test completed by two small Virginia stations, they argued that "the conclusion that a demonstration over short distances will make possible long-range synchronization of chain stations is unwarranted" because the conditions of the experiment were ideal. Such variables as distance, meteorological effects, and signal amplification would have to be accounted for before chain broadcasting could be synchronized effectively. ${ }^{44}$

At the prodding of the FRC, NBC began to seriously test synchronous broadcasting in late 1928. The experiments required close cooperation among Westinghouse, GE, NBC, and RCA engineers, as they involved stations KDKA (Pittsburgh), WGY (Schenectady, N.Y.), and WEAF (New York City). Carried on outside of normal broadcast hours, these initial tests uncovered a few new problems to be addressed. ${ }^{45}$ The commission's subsequent review called the results "unsatisfactory" because they uncovered a previously unknown type of heterodyne interference called "flutter interference." This type of interference was caused by the stations' carriers being closely, but not exactly, synchronized. This problem could be caused by a variety of factors, but the most prominent included distortion of the carrier wave by geophysical obstacles between the two transmitters. The key to avoiding flutter, according to FRC engineers, was to ensure minimal geographic separation. When synchronization under these conditions was achieved in a 1929 test, the results were far more promising. When two 5,000-watt stations located only 190 miles apart were synchronized briefly with the same program, they "were able to double the good-service area of either station alone" by eliminating those areas where heterodyne interference previously occurred. These results inspired Frederick Terman's vision

42. Ewin L. Davis to E. O. Sykes, 6 April 1928, published in Second Annual Report of the Federal Radio Commission (n. 30 above), 134.

43. "The Commission Suggests Synchronization Schemes," Radio Broadcast, January 1928, 200.

44. “The March of Radio: Will Synchronization Bring a Radio Panacea?" Radio Broadcast, May 1929, 8.

45. Thomas Porter Robinson, The Radio Networks and the Federal Government (New York, 1943), 232. 
of a national "interlocking group' system" for common frequency broadcasting. ${ }^{46}$ Clusters of synchronized transmitters would be carefully spaced apart so that their wavelengths would eradicate the zones where interference might occur.

In the spring of 1929, J. H. Dellinger, chief engineer of the FRC, proffered an optimistic view of the technical feasibility of a synchronous system:

If the frequencies of stations on the same channel are maintained to a certain very high accuracy, the heterodyne or whistle becomes inaudible. The technique of frequency control is fast approaching this goal and success has been attained in isolated instances. Synchronization is therefore looked for as the next great advance in broadcasting. ${ }^{47}$

By 1929, U.S. engineers, regulators, and listeners could point to at least two successful examples of synchronization: the WBZ-WBZA link, and an experiment conducted by WAIU in Columbus, Ohio, and KMOX in St. Louis in early 1928. A third could be found across the Atlantic. In the summer of 1928, Colonel A. G. Lee, the "radio expert" of the British Post Office Department, visited the United States to confer with U.S. broadcasters and regulators. Lee discussed the successful experiments whereby the urban centers in the United Kingdom were served by a series of low-powered (250watt) synchronized transmitters, while the rural regions were offered programming through a 25,000-watt transmitter. ${ }^{48}$

Acting by Dellinger's direction, the Institute of Radio Engineers' Committee on Broadcasting (made up primarily of engineers employed by the networks, RCA, Westinghouse, AT\&T, and the FRC) continued to promote synchronous-broadcasting experiments during 1930-31.99 The 1930 tests built upon the success of the 1929 experiments, which precisely was the problem as far as NBC was concerned. Testing occurred on the nights of 57 October 1930, between the hours of seven and eight. Under the guidance of C. B. Jolliffe, the newly-installed chief engineer of the FRC, and C. W. Horn, general engineer for NBC, for that one hour on three successive nights WEAF (New York City), KDKA (Pittsburgh), and WGY (Schenectady), all using the finest transmitting equipment possible, broadcast the

46. Fourth Annual Report of the Federal Radio Commission (Washington, D.C., 1930), 60; Terman (n. 2 above), 171-74.

47. J. H. Dellinger, "Engineering Aspects of the Work of the Federal Radio Commission," Proceedings of the Institute of Radio Engineers 17 (1929): 1332.

48. "Synchronized Broadcasting," Washington Post, 27 July 1928, 6; a report submitted to the Department of Commerce by engineers at WAIU and KMOX stated that synchronization had been achieved "with an entire absence of heterodyning"; "8 Stations Employ Same Wave Length," Washington Post, 21 October 1928, 5. On early BBC synchronization, see also Young (n. 3 above), 438-39, and Terman, 171.

49. "Reports of the I.R.E. Committee on Broadcasting," Proceedings of the Institute of Radio Engineers 18 (1930): 15-24. 
same programs on 660 kilocycles. There was remarkable improvement over the 1929 tests. Heterodyne interference in overlapping regions was considerably lessened, and the general reception area for the signal was greatly enlarged. NBC's president was forced to admit that "the problem of synchronized transmission has been solved." ${ }^{50}$ Commenting on the test, RCA's

JANUARY

2008

VOL. 49 chief engineer confidently predicted "that within the next few years synchronized networks will find practical application with the resulting advantage to the listener and broadcaster alike." ${ }^{1}$

Technical success created a dilemma for NBC's top executives. In a summary letter to the commission, Merlin Aylesworth admitted that "from a technical standpoint ... it is now possible to operate two or more stations on the same radio frequency without distortion." Yet he cautioned against excessive optimism: "Synchronization is a 'system' rather than any particular apparatus." He noted that the system had to conform to the structure of an established industry and warned that "hasty or immature practice or application" of the system would be problematic. "As the stations on present networks are all individually owned and serve important local interests, as well as national programs, they cannot and should not be operated in synchronism," he concluded. While admitting "the importance of synchronization in connection with network broadcasting," Aylesworth explained that "the difficulties in this connection must be carefully studied." He lobbied the FRC to look elsewhere for the widespread application of synchronism, writing that he was "confident the principles of synchronization can be satisfactorily applied to radio activities other than broadcasting, such as radio communications and television." 52

Despite Aylesworth's protestations, the FRC continued to encourage testing. The commission approved another series of synchronization tests involving several of the country's most important broadcast stations. These tests were conducted such that the stations' regular signals would not be affected in their primary markets and the results were closely monitored. If WTIC (Hartford), WEAF (New York City, the NBC Red flagship station), WJZ (New York City, the NBC Blue flagship station), or WBAL (Baltimore) complained about the experiment, it would have ended immediately. "These experiments," the commission concluded in its 1931 Annual Report, "are being observed very carefully, but as yet no general conclusions can be

50. "Refining Broadcasting," Washington Post, 24 October 1930, 6; "NBC Admits Practicability of Synchronizing" (n. 3 above), 364.

51. Alfred N. Goldsmith and Austin C. Lescarboura, This Thing Called Broadcasting (New York, 1930), 180. A second successful test from 1930, conducted by AT\&T engineers (involving two Iowa stations), is detailed in "Synchronized Broadcasting," Science 26 (1930): xii-xiii.

52. Merlin H. Aylesworth to General Charles McK. Saltzman, 20 October 1930, Federal Communications Commission Papers, box 399, file 89-6, record group 173, National Archives II, College Park, Md. 
drawn." Despite the reticence of the commission, the engineers involved informed the newspapers of both the successful transmissions and, importantly, the lack of listener complaints received. ${ }^{53}$

The FRC's reluctance to draw conclusions-and hence enforce synchronization-resulted not from issues of transmission, but rather reception. The 1930 and 1931 testing isolated the most important obstacle to synchronizing distant, high-power stations: the contemporary transmission antennae caused too much power to be radiated on the sky wave (as opposed to the ground wave). This created some reception difficulties in the shared bordering areas between the two stations. ${ }^{54}$ Engineers understood that phase distortion caused by time delays always represented a threat to the quality of a synchronized broadcast. Three factors played a role in ensuring quality reception of a synchronized signal: the field-intensity ratio of the carrier waves; modulation factors; and certain phase relations between the carriers and their accompanying side-frequencies. The field-intensity issue involved only the middle zones, where the signal strengths of the two transmitters were approximately equal. The FRC stated that a ratio of at least four-to-one in the intensities of the two synchronized radio waves must be achieved to prevent distortion, but this finding was disputed by most contemporary engineers, who believed a ratio of two-toone would suffice. ${ }^{55} \mathrm{In}$ fact, the distortion that actually occurred in the WJZ and WBAL tests happened only in a very limited bordering area near Wilmington, Delaware.

To eliminate both this distortion as well as the problems caused by the phase relations of the side-frequencies of the carrier waves, one AT\&T engineer confirmed Terman's hypothesis that any effective synchronous system required an increase in the "number of isochronously operated stations." Such an increase would both "improve markedly the satisfactoriness of the program received at a point distant from all the stations of the chain" and ensure the proper field-intensity ratios. ${ }^{56}$ This requirement for multiple transmitters with often overlapping signals appeared to make synchronous broadcasting more suited for regional, rather than national, broadcasting-

53. Fifth Annual Report of the Federal Radio Commission (Washington, D.C., 1931), 26-27; "New Radio Device Used without Hitch," New York Times, 17 March 1931, 37; "Synchronization Test Called Successful," New York Times, 2 April 1931, 33.

54. Fifth Annual Report of the Federal Radio Commission, 28. While admitting that the 1930 tests demonstrated that "advanced synchronization technique has great possibilities," William Wenstrom claimed that his alternative plan for equalizing the incoming reflected (ground and sky wave) signals using "long-wave Superbroadcasting" would be more simple and economic; see Wm. H. Wenstrom, "A Plan for Making National Broadcast Coverage Direct," Radio News, April 1931, 878-81.

55. Robinson (n. 45 above), 233-40; K. A. Norton, "Note on Synchronization of Broadcast Stations WJZ and WBAL," Proceedings of the Institute of Radio Engineers 22 (1934): 1087-89.

56. Robinson, 239. 
JANUARY

2008

VOL. 49

yet a national system was certainly not implausible. The experimentation during 1930-31 confirmed the technical practicality of such a system while raising the prospective costs involved (because of the additional transmitters required). An unnamed but clearly biased NBC source suggested to Electronics that, depending on several factors, national implementation could cost a network as much as $\$ 35$ million in new high-power transmitter costs. ${ }^{57}$

Despite this continued, promising testing, neither the FRC nor the chains nor Congress would seriously revisit the possibility of isochronous network broadcasting after 1931. By the time of the commission's fifth Annual Report, synchronization no longer appeared to be a solution to the problem of a crowded radio spectrum or a tool to increase the efficiency of chain broadcasting. The FRC switched its emphasis from network applicability to the development of more precise transmitting equipment. The results of further synchronization testing taught manufacturers ways to significantly reduce the frequency tolerance (minor, unintended frequency deviation) of transmitting antennae. By the time of the FRC's sixth Annual Report, the technical improvements in broadcasting resulting from the study of synchronization were being put into practice in transmitters throughout the country; however, any discussion of the connection between synchronization and network broadcasting had disappeared. In the commission's final report, synchronization was completely omitted.$^{58}$ Once the commission lost interest in applying synchronization to radio networks, this proposed alternative structure for U.S. network broadcasting would never again be seriously debated.

\section{Synchronization: The Lost Opportunity}

Although realistic consideration of an isochronous system ended for the most part by 1931, over the next several years references to synchronization continued to occasionally appear in discussions of the future of chain broadcasting. The commercial community's rejection of the system failed to deter various commentators from promoting its advantages. Synchronization, wrote influential radio reporter Martin Codel, "would

57. When the FRC ordered the WBAL-WIZ testing ended in 1932, it concluded that "synchronous operation of broadcast stations" would be most successful in cases involving "lower powered stations with more flexible installations and so located as to result in a minimum of inconvenience to radio listeners." "NBC's Synchronization Tests Ordered Ended by Commission," Broadcasting, 1 June 1932, 13; "NBC Admits Practicability of Synchronizing" (n. 3 above), 364.

58. Fifth Annual Report of the Federal Radio Commission, 22-23; Sixth Annual Report of the Federal Radio Commission (Washington, D.C., 1932), 28-29; Seventh Annual Report of the Federal Radio Commission (Washington, D.C., 1933). 
undoubtedly effect an economy of the all-too-scarce wave lengths. It may also mean the establishment of additional competing chains. The listener stands to benefit in any event." 59 "Synchronous broadcasting, begun in 1931 , if successful, should lead to an increase in the number of stations and also to greater development of the chain system," W. F. Ogburn optimistically prophesized in his 1932 report on "The Influence of Invention and Discovery" in Recent Social Trends in the United States: Report of the President's Research Committee on Social Trends. ${ }^{60}$

Such optimism was unfounded. By 1931, the public, political, and regulatory pressure on the broadcast chains had eased significantly. While testing of synchronous broadcasting continued, demands that networks be synchronized on a single wavelength disappeared from the public record. By successfully fending off isochronous broadcasting, the networks preserved a system designed to maximize their profits while minimizing competition.

Synchronous broadcasting represents a lost opportunity to democratize U.S. broadcasting. Considering its potential to alter the earliest debates concerning radio, it is particularly surprising that critics of the commercial system failed to promote its implementation. Synchronous broadcasting's ability to provide for a more democratic use of the airwaves-while curbing the expansion of the networks-is completely omitted in the historical scholarship of the early radio debates. In fact, it is unclear if commercial radio's critics were aware of synchronous broadcasting's promise. Focused almost entirely on commercial and cultural issues, they may have been blinded to technological alternatives to the status quo. Few of the prominent critics were engineers or physicists. James Rorty, one of the commercial system's most fervent adversaries, argued that spectrum scarcity required more governmental supervision over the airwaves - and, consequently, fewer broadcasting stations in America. In 1934, he called for a "re-designing of the broadcast system [so as to result in] a radical reduction in the number of stations." Other reformers like Ruth Brindze believed that the American system could be democratized by less radical means; she used spectrum scarcity to call for more regulatory activism in licensing procedures. For Joy Elmer Morgan, another prominent critic, the only solution to combat "the threat against free speech in America" represented by commercial broadcasting was "[s] tate control." 61 Yet such calls for state intervention did not unify the

59. Martin Codel, "The Radio Structure," in Radio and Its Future, ed. Martin Codel (London, 1930), 22.

60. W. F. Ogburn, with the assistance of S. C. Gilfillan, "The Influence of Invention and Discovery," in Recent Social Trends in the United States: Report of the President's Research Committee on Social Trends, vol. 1 (New York, 1933), 134.

61. James Rorty, Order on the Air! (New York, 1934), 26; Ruth Brindze, Not to Be Broadcast (New York, 1937), 289-92; "Commercial Radio Hit as Free Speech Peril," Washington Post, 13 May 1932, 3 (Morgan quote). 
JANUARY

2008

VOL. 49

reform movement; in fact, its chief weakness lay precisely in the movement's lack of unity. ${ }^{62}$ That few reformers were engineers partially explains this failure, as does the adversarial dynamic between the commercial broadcasting companies conducting synchronization tests and the reform movement.

For the commercial broadcasters, the single most effective weapon in combating political and regulatory pressure turned out to be unrelated to engineering or spectrum allocation. Beginning in 1929, the popularity of NBC and CBS among the listening public rapidly increased. It is no coincidence that public pressure for the single-wavelength system proved most powerful when the chief programming fare of the chains consisted of music-something listeners habitually received from multiple outlets across the country. Once the chains began offering new genres of programming, the American listening audience responded much more enthusiastically to their local presence. In the fall of 1929, NBC aired a series titled Amos ' $n$ ' Andy that would forever change U.S. radio. Amos ' $n$ ' Andy earned the highest ratings ever recorded in the history of U.S. broadcasting-it was truly a national phenomenon. Its primary legacy lay in the fact that it "did the preliminary work of conditioning listeners across the nation to following a continued radio program." 63 Shortly after its debut, NBC developed a program for Fleischmann's Yeast (starring Rudy Vallee) that proved enormously popular as well. In early 1930, the network created the first regularly scheduled evening radio drama, First-Nighter, which also secured a wide and loyal following. ${ }^{64}$

"There are two sides to the chain-program matter," Senator Dill explained in an earlier debate over synchronization. "When there is a great program of General Motors, for instance, or when Will Rogers or Al Jolson and other great entertainers are on the air, every station wants to be in on the program" because of the public acclaim these shows bestowed upon the local stations. ${ }^{65}$ Public dissatisfaction with program duplication was always closely intertwined with audience appreciation of some chain service. By the end of 1930, the U.S. audience, mired in economic despair, appreciated weekly visits from their national radio stars. As satisfaction with network programming increased, complaints to Congress and the FRC declined.

Synchronization lost its most enthusiastic proponent when Representative Davis lost a bid for reelection in 1932. The networks also proved more adroit in handling the intricacies of regulation after 1929; in that year, FRC commissioner Sam Pickard abruptly resigned his post in order to become

62. McChesney (n. 8 above), 261-62; see also Peter Morell, Poisons, Potions, and Profits: The Antidote to Radio Advertising (New York, 1937), 247-48.

63. Francis Chase, Sound and Fury: An Informal History of Broadcasting (New York, 1942), 181.

64. Harrison Summers, A Thirty-Year History of Programs Carried on National Radio Networks in the United States, 1926-1956 (New York, 1971 [1958]), 19-23.

65. Congressional Record, 70th Cong., 2d sess., 1929, 70:3753. 
a vice president of CBS. Pickard, who represented the zone that included Chicago, had been a particularly influential commissioner. ${ }^{66}$ Between 1930 and 1934, the networks developed the remarkably harmonious relationship with the commission that would characterize their interaction over future decades. ${ }^{67}$

In 1943, a young political scientist named Thomas Porter Robinson revived the idea of synchronous broadcasting by publishing an impressively detailed examination of U.S. network practice. Robinson's study relied heavily upon testimony compiled during the Federal Communications Commission's first investigation into chain-broadcasting practices conducted during 1938-39. He rediscovered synchronous broadcasting through the record of that investigation and contacted NBC's chief engineer, O. B. Hanson. While admitting that "synchronous network operation was feasible," Hanson clung to the company line by concluding that "serious distortion may occur at receiving points" and that the networks should not employ such a system until it was perfected. Robinson's review of the technical data effectively dismissed such concerns about reception. ${ }^{68}$

Robinson countered Hanson's pessimism with an examination of the global growth of synchronous broadcasting over the previous decade. By the mid-1930s, systems of isochronous network broadcasting had been successfully implemented in Great Britain, Germany, and Sweden. British technicians successfully created the first regularly scheduled wireless isochronous system by 1937, and throughout World War II engineers regularly improved the system. ${ }^{69}$ Even in the United States, in 1934, an improved system that synchronized stations WBBM in Chicago and KFAB, in Lincoln, Nebraska (on 770 kilocycles), offered results that "far exceeded the predictions of the most optimistic technical experiments." ${ }^{70}$ Clearly, by 1942, there existed no justified technical explanation for the system's rejection in the U.S. context.

Robinson concluded that economic considerations alone structured the networks' rejection of synchronization. The most serious difficulty presented by synchronization was the elimination of so-called split-network sales. Before World War II, neither NBC nor CBS had much success in selling the entirety of their chains to advertisers, who demanded "split networks," or radio chains in which only desirable markets would be pur-

66. “Capital Looms as a Center for Radio," New York Times, 17 February 1929, 130.

67. McChesney, 20-24.

68. Robinson (n. 45 above), 226-45; Hanson's remarks are on page 232.

69. Fritz Morstein Marx, "State Propaganda in Germany," in Propaganda and Dictatorship, ed. Harwood Lawrence Childs (Princeton, N.J., 1936), 28-30; Cesar Saerchinger, "Radio in Europe," Atlantic Monthly, April 1938, 512; Edward Pawley, BBC Engineering, 1922-1972 (London, 1972), 95-96, 164-65, 245-46; Young (n. 3 above), 438-39.

70. Young, 445; "The Present-Day Status of Broadcast Synchronizing," Electronics, June 1935, 174-78, 183. 
JANUARY

2008

VOL. 49

chased and linked. This required the networks to offer additional regional and local programming to affiliated stations bypassed by advertisers. From their inception, both CBS and NBC actually produced several "networks" on any given day, at the behest of advertisers. While CBS and NBC offered impressive national radio coverage, "hardly anybody buys the whole works," Fortune magazine noted in $1932 .{ }^{71}$ A system of unification upon a single wavelength represented the destruction of this flexible economic model. Robinson proposed that the networks be given two national wavelength assignments: one broadcast would carry the commercial program, and the second wavelength would carry the networks' sustaining broadcast for the bypassed stations. Such a system would increase competition in network broadcasting - something interesting to both the FCC and the Roosevelt administration. "If from the economic and social standpoints synchronous network broadcasting is shown to be feasible and in the public interest, confidence is justified that whatever obstacles to its achievement exist today can be overcome," Robinson concluded. ${ }^{72}$ The broadcasting community ignored his argument; a critical review of his book in Broadcasting entirely omitted discussion of this central idea. ${ }^{73}$

\section{Conclusion}

For economic and regulatory reasons, synchronous broadcasting was simply too dangerous for the commercial community to contemplate. It partially resolved the U.S. system of broadcasting's essential regulatory (and competitive) dilemma: spectrum scarcity. In 1935, when 625 stations were licensed to broadcast in the United States, knowledgeable engineers estimated that synchronization could result in the accommodation of as many as 6,000 stations on the broadcast band. ${ }^{74}$

The scarcity argument provided the technical rationale for the domination of the networks. It allowed them to proclaim that their oligopoly was ordained by nature and made their enormous success appear innate rather than manufactured. "I can see the possibilities of developing systems of inter-communication ... that will not depend upon wires at all," David Sarnoff, NBC's chairman of the board, told the FCC in 1939. "You can carry these signals ... by means of a radio line instead of a wire line . . by utilizing radio relays," he explained. "When these developments are perfected, as I believe they will be, in time ... you will have more technical facilities avail-

71. “An Appraisal of Radio Advertising Today," Fortune, September 1932, 94.

72. Robinson, 227-28.

73. "Network Rules Attacked in New Book," Broadcasting, 14 June 1943, 16.

74. United States Bureau of the Census, Census of Business, 1935: Radio Broadcasting (Washington, D.C., 1936), 2; “The Present-Day Status of Broadcast Synchronizing," 183. 


\section{SOCOLOW | Synchronous Broadcasting}

able for use than there will be people to use them."75 These comments echoed his earlier statements about the future of chain broadcasting:

I can see the day when there will be more networks possible, technically, than people to use them. There is no reason I can see why there can't be a dozen, or two dozen, or several dozen national networks, but in order to have them it is necessary to develop waves in that part of the ether which may be characterized as wasteland. ${ }^{76}$

Sarnoff prided himself on his technical expertise; thus he was undoubtedly aware of synchronous broadcasting. His testimony placed isochronous broadcasting far in the future, therefore protecting a franchise too valuable to alter. By 1938, the technology existed, though the will to implement it had gone missing.

75. David Sarnoff, Principles and Practices of Network Radio Broadcasting (New York, 1939), 50.

76. Federal Communications Commission Docket No. 5060, 8520. 